\title{
Relying on "Innovation and Entrepreneurship Platform", Strengthen the Construction of Public Research Universities Peoples Entrepreneurial Innovation Base
}

\author{
Junzheng Wang, a and Guixue $\mathrm{Hu}^{1, \mathrm{~b}}$ \\ ${ }^{1}$ Xincheng Street 2888, Changchun, Jilin Province 130118, PR China \\ a59545966 @ qq.com, bouixue1964@126.com
}

Keywords: Ordinary colleges and universities; Innovation and entrepreneurship; Base construction; Model

\begin{abstract}
This paper focus on how to rely on the "Innovation and Entrepreneurship platform" from under the background of economic new normal colleges and universities, innovation base construction of expounds main problems existing in the base construction of the necessity and importance and base construction, explore the base construction of the "12345" mode, according to the school practical innovation and entrepreneurship existing platforms, from student training, teaching other point of view, the practice of the relevant requirements of relevant national policies, answer questions innovation base construction of College.

Recently "the State Council on the implementation of the construction of public opinion highly innovative entrepreneurship demonstration bases," the introduction, announced the first list of 28 demonstration bases, including four University, Tsinghua University, Shanghai Jiaotong University, Nanjing University and Sichuan University, which is domestic innovation based entrepreneurship education superior four universities, the country now has more than four to give policy support to colleges and universities, the advantages will become increasingly evident, other colleges and universities if does not strengthen the construction, innovation and entrepreneurship base exists the gap will become more and more.
\end{abstract}

\section{Carry out the Construction of Public Peoples Entrepreneurial Innovation Base in Colleges and Universities Significance}

To Strengthen the "Innovation and Entrepreneurship" Base Construction Is Realistic Demand for Innovation and Entrepreneurship Bases under the New Economic Normal Background. As China's economy entered a new normal, namely: economic growth shifting down, the rapid growth of the norm; along with supply-side reform and structural optimization and upgrading become the norm; investment-driven to innovation - driven change has become the norm; various uncertain risks appear of the norm; macro-control concepts and innovative ideas become the norm [1]. In the new normal economic background, Premier Li Keqiang at the Davos Forum proposed "mass Peoples entrepreneurial innovation," the State Council recently issued the "Opinions building public Peoples entrepreneurial innovation demonstration base", ordinary university innovation base also should take this as an opportunity, relying on the existing "Innovation and Entrepreneurship" platform for effective construction, and university personnel training center to practice positioning, innovation and entrepreneurship needs a really good job under the new normal, and make effective adjustments. Public entrepreneurship peoples innovation base construction is not only the integration of the software environment of the strong humanities and social feelings, and integration with the professional, scientific research, experimental platform and the school business park hardware advantages, thus for students provides a perfect knowledge, knowledge and experience and combining the practice base; at the same time this very innovative practice teaching mode, with the greatest potential for mining students' innovation consciousness, the simulation of practical science and technology innovation development process and steps [2].Students in the Improvement of scientific and technological innovation and entrepreneurship, based on the employment of college students can not only enhance self-confidence, and effectively 
improve students' employment rate, and can promote the development of scientific and technological innovation and technological innovation level of the country's colleges and universities.

To Strengthen the "Innovation and Entrepreneurship" Bases at Home and Abroad "Innovation and Entrepreneurship" Bases Development Status of Practical Needs. Research on college students venture base began in the last century describe college students venture base eighties, more comprehensive system, and to belong to the UNDP in 1996 published "Economic Development Business Incubator," the paper elaborated Students defined entrepreneurial base, function and role of management status and development trend, but also stressed the important role of entrepreneurial university bases and impact on the local and national economic development [3].With the rapid economic development of university business park has been playing an increasingly important role in innovation and entrepreneurship education to carry out the process. By studying Chinese literature database found fewer articles on domestic innovation base of the College. Among them, Mo Weiwei "college students venture incubator of construction," Zhang Haomin "Mining and Integration of entrepreneurship education functions in University Incubator Pioneer Park "and so on. These studies mainly focus on the analysis of the current situation of the university students' Pioneering Park, the construction of the University pioneer parks and the research of the innovation and entrepreneurship education mode. After control at home and abroad, we also found a number of situations: First, the "Innovation and Entrepreneurship" platform and the combination of innovation and entrepreneurship education, particularly at the low correlation study how to highlight its educational core functions. Second, relying on the "Innovation and Entrepreneurship" platform to promote a virtuous cycle of innovation and entrepreneurship education research that is less [4].Third, how to play a "Innovation and Entrepreneurship" platform less aspect of the study as the most important carrier to carry out the innovation and entrepreneurship education. Fourth, play baton policy function, and promote long-term mechanism less research base for the healthy functioning of the Innovation and Entrepreneurship which is the main problem and the innovation of this study that is to be solved by relying on the existing "Innovation and Entrepreneurship" platform for universities, colleges and universities to strengthen pubic Peoples entrepreneurial innovation bases.

To Strengthen the "Innovation and Entrepreneurship" Construction is the Realistic Requirement of the New Era of College Students' Innovation Ability Training Practice. Today, national policy guidance and personality characteristics of the new era of college students and other factors, have prompted the College of Jilin Province to step up the pace, relying on the "Innovation and Entrepreneurship" platform, based on the original platform for innovation and entrepreneurship to lead the ideological, institutional improvement, aspects of equipment and facilities upgrades, teaching staff, support services were strengthened to meet the new era of innovation and entrepreneurship training college students, the practice needs to give these young people full of passion and keep dreaming of the opportunity to "trial and error", allowed experience the school, society and the state to have innovative entrepreneurship the importance of talent, time and the ability to exercise the students during the correlation found related problems, and actively communicate with the instructor to solve, so that in the "in school" campus practice innovation and entrepreneurship" after graduating from" outside the campus realize innovation and entrepreneurship, and enhance the quality of their own at the same time, and strive for the economic construction and development dedicated force [5].

\section{The Main Problem of the Highly Entrepreneurial Innovation Bases Colleges Public}

The Last Mile Problem of the Formulation and Implementation of Relevant Policies. To strengthen innovation and entrepreneurship education, promoting economic and social development, the State Council issued a series of provincial and municipal policy documents, after several years of exploration and practice, College Students Pioneer Park building has achieved remarkable results, supporting a number of typical entrepreneurial, developing vigorously of innovation and entrepreneurship education[6].Attendant also generated a lot of problems to be solved and 
construction management problems, how to find the cause of the problem, to tease out the solution to the problem, which is particularly necessary. And due to environmental conditions and various universities and other factors, there is no part of the policy put in place, the majority of colleges and universities have not established Institute of innovation and entrepreneurship, innovation and entrepreneurship education cannot be classified as a required course, we should make efforts to solve the last kilometer innovation and entrepreneurship policy issues to promote research "Innovation and Entrepreneurship" base healthy functioning aspects of long-term mechanism to play the role of baton-related policies, strengthen supervision and guidance, the role of the university in command, supervise the implementation of specific policies [7].

The Lack of Effective Mechanisms for Cooperation between Enterprises. At present, in the construction of the "Innovation and Entrepreneurship", many colleges and universities are lack of school enterprise cooperation system mechanism, have not formed a good long-term mechanism. Enterprise personnel to the school to lecture to the channel by the restriction of teaching management system, is not unimpeded[8]; especially teachers teaching business class teachers, most of the administrative staff part-time to part-time business, there are still some difficulties; students to the enterprise practice time and certain constraints. German "Dual System" training mode to provide "order form" a good reference model, it is supplemented by teaching colleges, corporate training mainly institutions to require students in the school entered into employment or training on the enterprise contract business as the central subject of vocational training, to actively participate in cooperative education, and consciously undertake the task of training personnel involved in recruitment from colleges and universities throughout the personnel training graduation process. Another example is "Working and Learning Alternation" mode, "internship" mode, "Combination" mode of school-enterprise cooperation model, can be a good practice to promote student innovation and entrepreneurship skills development.

Lack of Incentives for Teachers in the School. College on full-time or part-time teacher-related incentives for innovation and entrepreneurship is not perfect. Some only knowledge transfer, training and learning opportunities to go out is too small, leading to innovation and entrepreneurship lessons teachers' knowledge, the speed is slow, cannot meet the requirements of a new generation of innovation and entrepreneurship courses. Some colleges and universities, teachers engaged in other research papers with titles and relevant content, innovation and entrepreneurship education activities, are not enthusiastic. Through research and learning, good understanding of the domestic colleges and universities incentives, such as Jilin University, China People's University and other universities, giving Challenge Cup Business Plan Competition Gold Project Steering education, from associate professor titles can be directly appointed professor of incentives, greatly mobilized the enthusiasm of teachers, we can summarize the relevant policy analysis and research, scientific development of related systems, actively encourage and support teachers to join the innovation and entrepreneurship education and guidance activities, encouraging students to actively participate in the innovation and entrepreneurial activity [9].

Inadequate Incentives for Students. The current policy slower landing or some worse implementation, some of the policies related support needs in order to better assist policy purposes. Such as innovation and entrepreneurship students to participate in after-related game and get the appropriate ranking, can replace some of the subjects test scores, updates, innovation and entrepreneurship, but most of the work cannot be a good policy support, leading students to participate in activities, competitions and practices enthusiasm is not high It should be on the basis of full investigation, combined with the school talent fostering the development of relevant policies to establish long-term mechanism.

\section{The Construction of College Public Entrepreneurship Peoples Innovation Base Construction of the "12345" Mode}

To solve the above problems, co-ordination of all resources, relying on the existing platform for innovation and entrepreneurship colleges and universities to build "12345", "Innovation and 
Entrepreneurship "base-building and the strengthening of Jilin College student innovation and entrepreneurship bases.

"1" refers to the integration of training, practice platform, that public Peoples entrepreneurial innovation base. College training base for innovation and entrepreneurship in the relevant policy guidance groups, one based on professional practice and training, to enhance practical ability, and gradually form a set theory, training, incubation for one, with the school and outside the exchange market integration ecological operation system; the second is school-enterprise cooperation as the basis, to solve practical problems; Third, it results into a link, teachers and students to participate.

"2" refers to the two platforms, namely research and innovation platform for schools (including research centers, research centers, engineering centers, laboratories and so on.) and business platform (including Schools in two business park, business base, a passenger space and so on.) . In the innovation platform, the realization of "theory - practice - Creativity - Competition" loop iteration progressive mode; in the business platform, the realization of "theory - Training Competition - incubator" progressive mode cycle, and by the two platforms competition and integration of scientific research into the link operation.

" 3 " refers to the three-oriented, that is, for students, for teachers, and the community (including business and actual production). On the one hand, all the "Innovation and Entrepreneurship" platform is open to students, teachers; students complete basic theoretical study and practical platform for innovation inherent in the guidance of teachers, students can either produce their own ideas and the formation of practice, may be added to the teacher's scientific research, participate in relevant research and relying on science and technology competitions, through the transformation, transport venture to Pioneer Park. In the business platform, teachers and students can be their own entrepreneurial projects incubation, through the integration of resources, team building, actual operations and other items running. On the other hand, these two platforms in innovative sources to follow the market demand, followed by production problems and needs that exist in reality, that is, for the community [10].

"4" refers to the four guides, namely government-oriented, market-oriented, problem-oriented, eco-oriented. Government guide: Now associated policy documents have been issued, ordinary college students innovation base construction will also be combined with an existing platform, with specific policies to improve gradually, to create a more adapt to new and innovative entrepreneurship "Innovation and Entrepreneurship" base built environment base. Market orientation: take advantage of today's market demand for socio-economic development efforts of the students and teachers of ideology, theory-oriented, practical training is inclined to the market demand, the market needs to do to fully boot the basis of the idea of innovation and entrepreneurship. Problem-oriented: Looking to explore the difficulties of today and the actual production problems and need to be addressed, give full play to the new generation of college students a unique way of thinking and keep dreaming of character, combined with the adjustment of school innovation base construction, efforts will be problem-oriented integration of teaching and student innovation and entrepreneurship ideas go, this also increases the success rate of innovation and entrepreneurship project continued transformation from nature. The Ecological: at the political, ecological and economic context, improving innovation base of the function, which is to create a good "Innovation and Entrepreneurship" ecological, so as to promote innovation and entrepreneurship base continue to build more innovative and to explore innovation base mode.

"5" refers to the five levels, namely innovation base operation "theory - Training - Creative Competition - incubator" five levels. Professional courses as the core, innovation and entrepreneurship education curriculum-based, increase KAB, SIYB courses, form a good theoretical basis for innovation and entrepreneurship courses around, and then to enhance innovation and entrepreneurship skills through basic training, practice, and thus in practice the practical problem is formed innovation and entrepreneurship concept is creative, and use relevant competition validation and improvement ideas, which will culminate in innovative entrepreneurial projects incubation, and through various aspects of the complete innovation base service system to support, to achieve the 
innovation base from theory to practice to start a business in the whole chain of ecological functions operate.

This "12345", "Innovation and Entrepreneurship" base-building mode, run ecological long-term mechanism to be formed, the policy also needs to play a baton function, it is necessary to implement a policy to solve the problem of the last kilometer, the creation of innovation and entrepreneurship will be a required course or elective, strengthen school yard Pioneer Park building at all levels to implement the number one project, the establishment of innovation and entrepreneurship in the College under conditions permitting, coordination of resources, promote a virtuous circle; while examining the analysis, domestic university teachers to guide students to innovation and entrepreneurship, and students to participate in innovation and entrepreneurship incentive policy, science and formulate relevant policies to encourage and support teachers and students to join the innovation and entrepreneurship education and practice.

\section{Conclusion}

In the new normal economic background, relying on the "Innovation and Entrepreneurship" platform for Peoples entrepreneurial and Public innovation bases have become a trend, under the guidance of national, provincial and municipal policies, in the "twin engines" driving the economic development of the appeal, in innovation-driven development strategy under the guidance in the process of building an innovative country in various colleges and universities, will intensify its efforts to integrate resources to enhance public Peoples entrepreneurial innovation base construction, innovation and entrepreneurship for teachers and students to provide support integrated training practice, for local construction economy and regional economic development bred more and more outstanding force.

\section{Acknowledgements}

Project 1:2015 Jilin Province Educational Science "12th Five-Year" general planning topic < Ordinary Higher Agricultural College Students Innovation Talent Training Mode Research > research results (No.: GH150216)

Project 2: One of the results of "agricultural university students study entrepreneurship education system", Jilin Provincial Department of education "12th Five-Year" social science research project (ID: Jilin Education Science topics [2015] NO.118)

\section{References}

[1] Wang Jun. Cohesion of China's economic "new normal" positive energy (J). Lookout, 2014,24 (22): 1

[2] Yang Yan, Ai Zhiqiang, Shen Yuanjun. Discussion on College Students' innovation base construction [J] Liaoning University of Technology (Social Science Edition), 2013, 32 (11): 58-60.

[3] Li Changxi, Zhang Weiwei, Li Jiannan. The construction and practice of innovation and entrepreneurship education platform for engineering college students [J]. Heilongjiang higher education research, 2014, 04: 97-99.

[4] Liu Ying. Science and Technology Innovation and Entrepreneurship Talent Training Mode of [D]. Harbin Polytechnic University, 2015.

[5] Guan Yifeng, Gao Hui. to promote innovation and entrepreneurship education Universities Situation and Countermeasures [J] Jiangsu Radio \& Television University, 2011,06: 77-79.

[6] Li Wenkai, Liu Ying, Li Ye. Universities of innovation and entrepreneurship education training program and teaching plan [J] Baicheng Normal University, 2012, 01: 14-17. 
[7] Jing Hongjun, Wang Yunbo, Jin Yi. Students social practice to promote innovation and entrepreneurship education in Institutions of higher learning [J]. Economic research Herald, 2012, 14: 250-251.

[8] Wuyan Tao, Han Tongji, He Jing, Agricultural Colleges and Universities, "three-step" Innovation and Entrepreneurship Education Model [J] Shenyang Agricultural University (Social Science Edition), 2012,06: 698-700.

[9] Feng Xiao. The practice and exploration of innovation and entrepreneurship education in agricultural colleges and universities [J]. China's agricultural education, 2015, 05:1-7.

[10] Huang Wei, Jia Fengrui, Li Yanbin, Sun Wenzhuo, Zhang Ruijun. Universities Innovation and Entrepreneurship Education Construction [J] innovation and entrepreneurship education, 2016, 01: 38-40. 